\title{
Synthesis and Characteristic of Precipitated Nano-Silica
}

1st M. Sadeghi, 2nd M. Dorodian ,3rd M.Rezaei

1st Sharif Nano Pigment Co. (SNP), institute of colorants, paints\& coatings (ICPC), Technology development institute (ACECR), Tehran, Iran

mohammad.sadeghi@mdh.se

2nd Technology development institute (ACECR), Tehran, Iran

mdourodian@gmail.com

3rd Sharif Nano Pigment Co. (SNP), institute of colorants, paints\& coatings (ICPC)

Masoomeh.62@gmail.com

\begin{abstract}
:
The reaction of precipitation of amorphous silicon dioxide from aqueous solution of sodium silicate and sulfuric acid has been studied. The factors affecting the precipitation process of the sodium silicate solution such as sodium silicate concentration and addition of anionic surfactant (sodium dodecyl sulfate, SDS) on particle size, size distribution and degree of agglomeration of the precipitated silica were examined. The precipitation of silica from the produced sodium silicate solution was carried out using sulfuric acid at $\mathrm{pH}$ 7. Scaning electron microscope (SEM), transmission electron microscope (TEM) and Dynamic light scattering (DLS) have been used for characterization of the produced nano-silica. The surface area of silica was tested by oil absorption method according to ASTM standard. Results showed that the particle size of the precipitated silica gel was decreased with increasing Na2SiO3 and SDS concentrations and Particle size of about $44 \mathrm{~nm}$ can be achieved at $20 \% \mathrm{Na}_{2} \mathrm{SiO}_{3}$ and $200 \mathrm{ppm}$ SDS. But with decreasing particle size, degree of agglomeration also increased.
\end{abstract}

\section{Keywords:}

Silica nanoparticles; precipitation; particle size; sole gel

\section{Academic Discipline And Sub-Disciplines}

Materials Science

\section{SUBJECT CLASSIFICATION}

Chemistry Subject Classification

\section{TYPE (METHOD/APPROACH)}

Experimental study-nano fild

\section{Council for Innovative Research}

Peer Review Research Publishing System

Journal: Journal of Advances in Chemistry

Vol. 6, No. 1

editor@cirworld.com

www.cirworld.com, member.cirworld.com 


\section{Introduction:}

Producing of fine and uniform precipitated silica is of interest in scientific and technological point of view. Silica nano particles are used in wide range of application including filler in tires, catalyst, toothpaste, wet absorbent materials. Moreover, silica nano particles are used in many fields such as ceramics, chromatography, electronic substrates, thermal and electrical insulators, humidity sensors and optoelectronic devices [1-4].

Many investigator implemented sodium meta silicate and some kind of acid as reactive substances for sol-gel preparation of silica particles [5,6]. Particle size and particle distribution are very important characteristic of precipitated silica during its usage. Among affective parameters, concentration of reactive substances has a great effect on the particle size and size distribution of precipitated silica. Controlling the particle size and distribution in sol precipitation continues to be a major concern in the production of advanced ceramics. According to the Bogush and Zukoski's model [1, 4], which describes the particle growth of silica in sol precipitation, stable silica particles are formed and grown via the aggregation of primary particles that are nucleated in a supersaturated solution. Therefore, the particle size and distribution change significantly according to the solvent, solution $\mathrm{pH}$, and reactant concentrations, all of which affect the nucleation and aggregation of the primary particles. A multi-modal particle size distribution can be obtained by modifying the particle nucleation and growth processes via varying the reactant concentrations. Surfactants are often applied to the solprecipitation process to control the size and uniformity of silica particles. A uniform particle size originates from the molecular interaction with the surfactant provides the driving force for particle aggregation [7-9].

In this work, two factors affecting the precipitation process of the sodium silicate solution such as; sodium silicate concentration and addition of anionic surfactant (sodium dodecyl sulfate, SDS) on the particle size, size distribution and degree of agglomeration of the precipitated silica were studied.

\section{Experimental procedure}

Silica was obtained in precipitation reaction from aqueous solution of sodium metasilicate and Sulfuric acid. Sodium dodecyl sulfate (SDS) was used as a surfactant. The precipitation reaction takes place according to Eq.1.

$\mathrm{Na}_{2} \mathrm{SiO}_{3}+\mathrm{H}_{2} \mathrm{SO}_{4} \rightarrow \mathrm{SiO}_{2} \cdot \mathrm{H}_{2} \mathrm{O}+\mathrm{Na}_{2} \mathrm{SO}_{4}$

At first aqueous solutions of sodium metasilicate with 10, 15 and 20 (wt.\%) concentrations of sodium metasilicate were prepared. Exact amount of SDS according to table.1 was added to each solution. Then the solution was heated up until the temperature $85^{\circ} \mathrm{C}$ was reached. At the same time it was stirred with propeller at 500rpm to obtain a homogeneous solution. The precipitation of silica was carried out by sulfuric acid. The acid with $4 \%$ concentration was added gradually to the solution until $\mathrm{pH} 10$ was attained. Then acid with $1 \%$ concentration was added until $\mathrm{pH} 7$ was reached. The resulting suspension was mixed for additional one hour. The silica gel formed was washed with deionized water and dried. Drying was carried out with spray dryer (BUCHI Mini Spray Dryer B-191). Each experiment was carried out three times to eliminate probable mistakes. The surface area of the silica was measured by oil absorption method according to ASTM D 281-95 standard. Nine experiments were carried out in order to evaluate the effect of metasilicate and SDS concentrations on the particle size and size distribution of precipitated silica according to the table 1.

Table.1: mean particle size and oil absorption of $\mathrm{SiO}_{2}$ at different reactant concentration

\begin{tabular}{|c|c|c|c|c|c|}
\hline $\begin{array}{c}\text { Experiment } \\
\text { number }\end{array}$ & $\begin{array}{c}\text { Meta silicate } \\
\text { concentration } \\
\text { (wt.\%) }\end{array}$ & $\begin{array}{c}\text { SDS } \\
\text { concentration } \\
\text { (ppm) }\end{array}$ & $\begin{array}{c}\text { Mean } \\
\text { particle size } \\
(\mathrm{nm})\end{array}$ & $\begin{array}{l}\text { Standard } \\
\text { deviation } \\
\text { (nm) }\end{array}$ & $\begin{array}{c}\text { Oil absorption } \\
\text { (gr oil/100gr } \\
\text { silica) }\end{array}$ \\
\hline 1 & 10 & 0 & 1140 & 1220 & 42 \\
\hline 2 & 10 & 100 & 1030 & 1130 & 79 \\
\hline 3 & 10 & 200 & 850 & 690 & 83 \\
\hline 4 & 15 & 0 & 1010 & 980 & 77 \\
\hline 5 & 15 & 100 & 620 & 830 & 98 \\
\hline 6 & 15 & 200 & 160 & 70 & 146 \\
\hline 7 & 20 & 0 & 220 & 105 & 137 \\
\hline 8 & 20 & 100 & 170 & 80 & 179 \\
\hline 9 & 20 & 200 & 74 & 38 & 296 \\
\hline
\end{tabular}


The produced silica was studied by scanning electron microscopy (SEM) and transmission electron microscopy (TEM) in order to obtain data on particle size, particle size distribution, particle shape and degree of agglomeration. Images obtained from electron microscopy were evaluated with image analyzer software and particle size and particle distribution of the particles were determined. For more precise measuring of particle size and particle distribution of silica particles which was obtained from optimum condition, dynamic light scattering (DLS) method was used.

\section{Results:}

Production of precipitated silica nano particles from sodium silicate solution with sulfuric acid at $\mathrm{pH} 7$ is according to the Eq No.1. The effect of two variables (sodium silicate concentration and SDS concentration) on the particle size of precipitated silica was studied and the results are presented in Table.1.

\subsection{Effect of sodium silicate concentration}

Fig. 1 illustrates the effect of sodium silicate concentration on the particle size of precipitated silica at constant SDS concentrations. From this figure, the particle size of precipitated silica decreases with increasing of sodium silicate concentration at different concentrations of SDS. Results show that sodium silicate concentration has great effect on the precipitated silica size. With increasing concentration of sodium silicate from 10 (wt.\%) to 20 (wt.\%), the average size of precipitated silica decreases from $1030 \mathrm{~nm}$ to $170 \mathrm{~nm}$ at $100 \mathrm{ppm}$ SDS and from $850 \mathrm{~nm}$ to $74 \mathrm{~nm}$ at $200 \mathrm{ppm}$ SDS. The change in the particle size can be attributed to the change of the nucleation and growth rates of the produced silica particles. Increasing of sodium silicate concentration led to increase the nucleation rate of the formed silica particles which increase the fine particles as well as increasing growth rate of already silica particles.

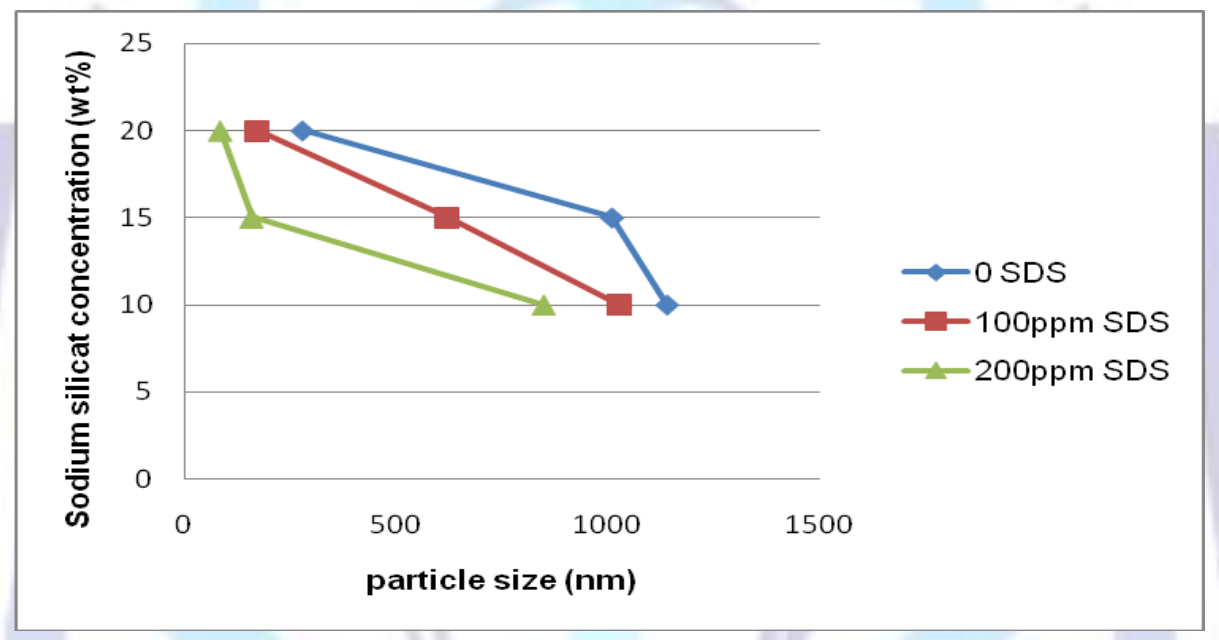

Figure. 1: effect of sodium silicate concentration on the particle size of precipitated silica on three different SDS concentrations

Fig. 2 shows SEM images of precipitated silica with 10 (wt.\%) and 20 (wt.\%) concentrations of sodium silicate at constant $200 \mathrm{ppm}$ of SDS. From this figure, it can be seen that particle size of silica deceases with increasing metasilicate concentration. Agglomeration of silica particles produced at 20 (wt.\%) metasilicate and 200 ppm SDS is observed in this figure.
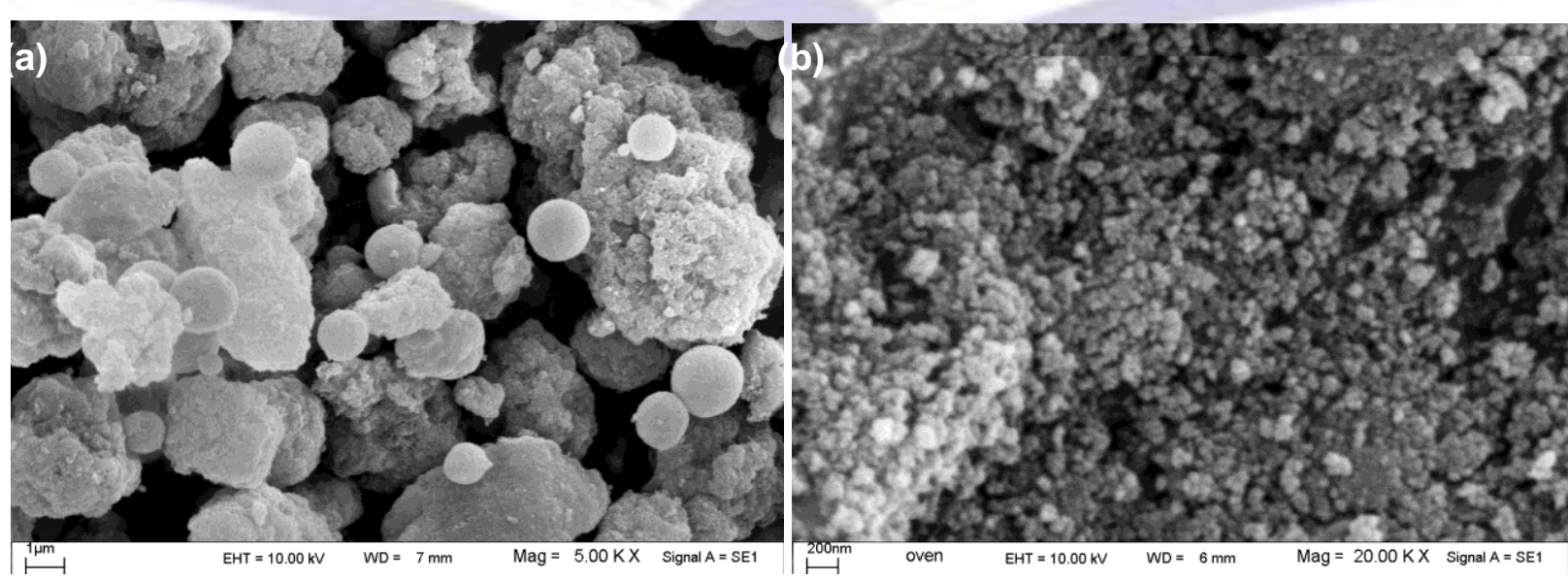

Figure.2: image of precipitated silica with a) 10 (wt.\%) concentration and b) 20 (wt.\%) concentration of sodium silicate at constant 200ppm SDS 


\subsection{Effect of SDS concentration:}

Fig. 3 indicates the effect of SDS concentration on the particle size of precipitated silica. It can be observed that SDS concentration has significant effect on the particle size of precipitated silica at constant sodium silicate and sulfuric acid concentrations. For example the mean size of the silica particles decreases from $220 \mathrm{~nm}$ to $74 \mathrm{~nm}$ with increasing of SDS concentration from 0 to 200ppm at constant 20 (wt.\%) concentration of sodium silicate.

According to the theory of homogeneous nucleation, the nucleation rate increased as the interfacial surface tension decreased. As the surfactant dramatically lower the surface tension, their presence in solution strongly increases the nucleation rate, and the particle size decreased. This means that SDS, as surfactant, is playing an important role in modifying the size of the particles. Addition of SDS surfactant increases the nucleation rate and increases the growth rate through networking of formed nuclei of the produced silica particles. High nucleation rate means that a high number of formed nuclei are obtained. These nuclei have relatively low chance to grow to large particles compared to lower number of formed nuclei which grow under the same conditions. However, at high surfactant concentration, the surfactant molecules forming micelles, therefore, high attraction force was obtained.

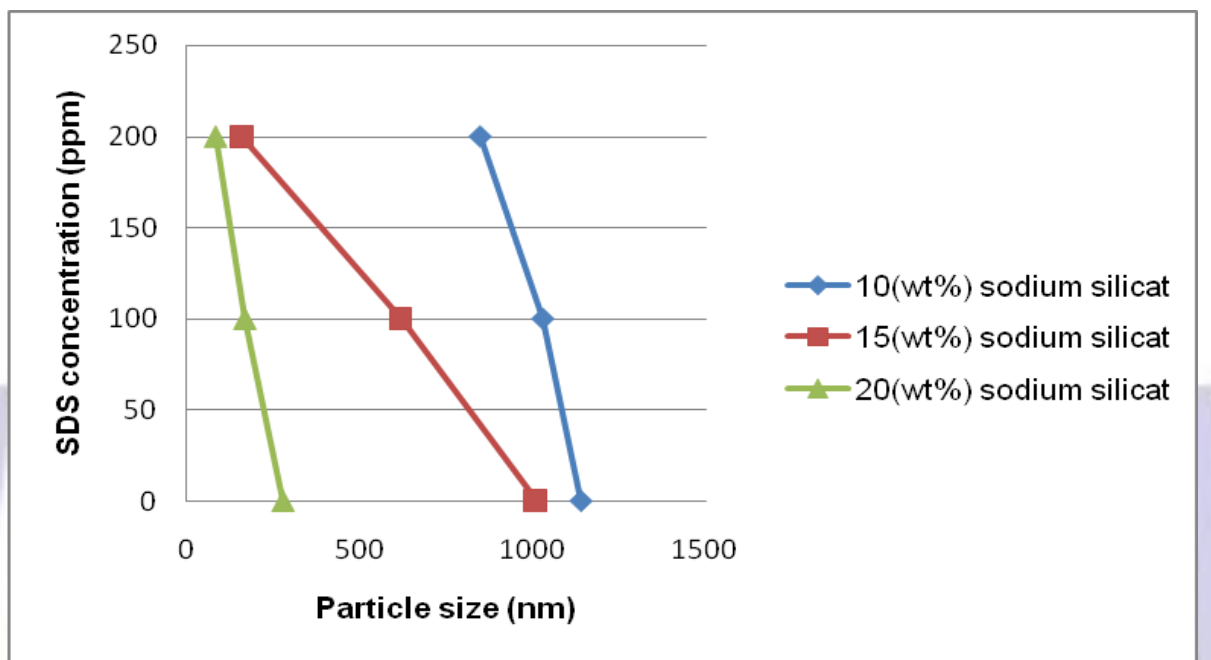

Figure.3: effect of SDS concentration on the particle size of precipitated silica

\subsection{Characteristic of produced precipitated silica:}

Fig. 4 represented XRD analysis of the produced silica. It observed that the produced silica was amorphous.

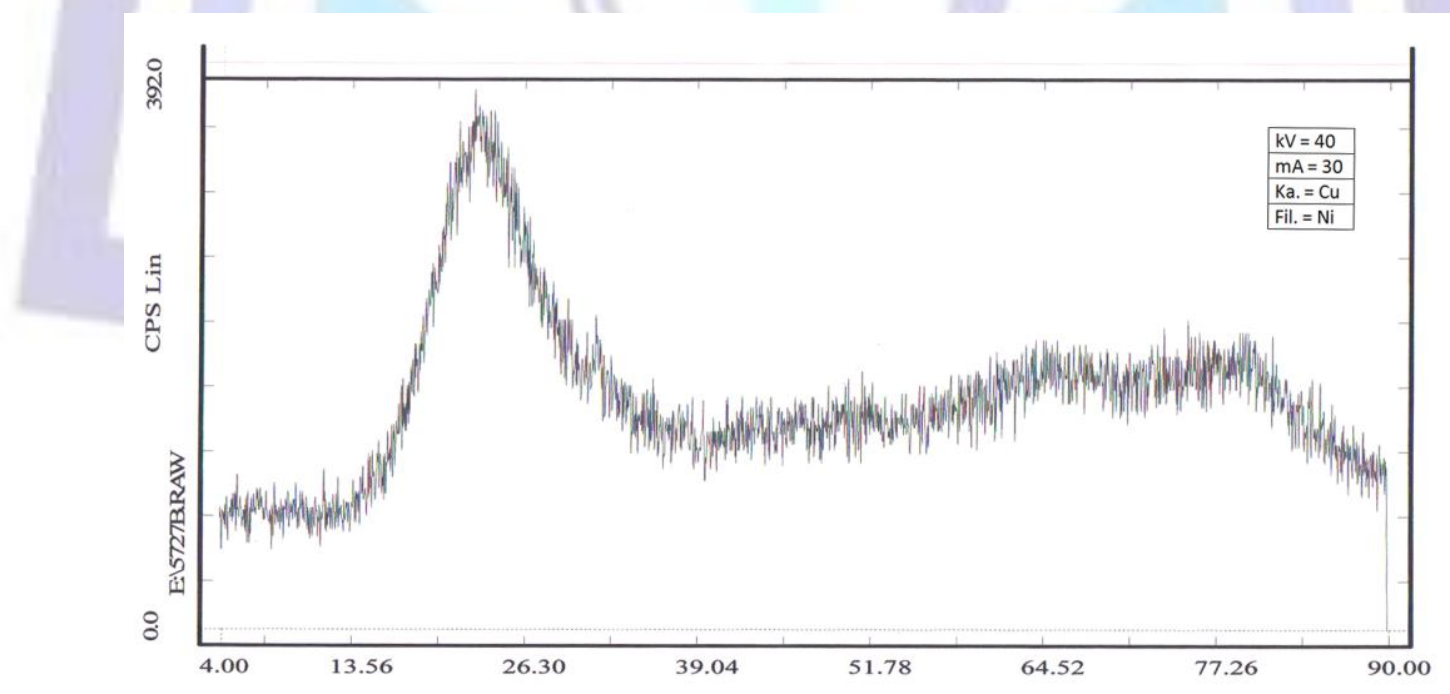

Figure. 4: XRD analysis of the produced silica

The building block of silica is the $\mathrm{SiO}_{4}$ tetrahedron, four oxygen atoms at the corners of a regular tetrahedron with a silicon ion at the central cavity or centroid. The oxygen ion is so larger than the $\mathrm{Si}^{4+}$ ion that the four oxygen atoms of a $\mathrm{SiO}_{4}$ unit are in mutual contact and the silicon ion is said to occupy a tetrahedral hole. In amorphous silica, the bulk structure is determined by random packing of [SiO4] ${ }^{4-}$ units, which results in a nonperiodic structure [5]. Fig. 5 shows DLS analysis of produced nano-silica particles (experiment No. 9 in table 1). This graph indicates the uniform size distribution of 
precipitated silica. As can be seen from this graph, particle sizes are between $20 \mathrm{~nm}$ to $110 \mathrm{~nm}$ and most of the particle sizes are between $37 \mathrm{~nm}$ to $58 \mathrm{~nm}$. The Average size of the particles is $44 \mathrm{~nm}$.

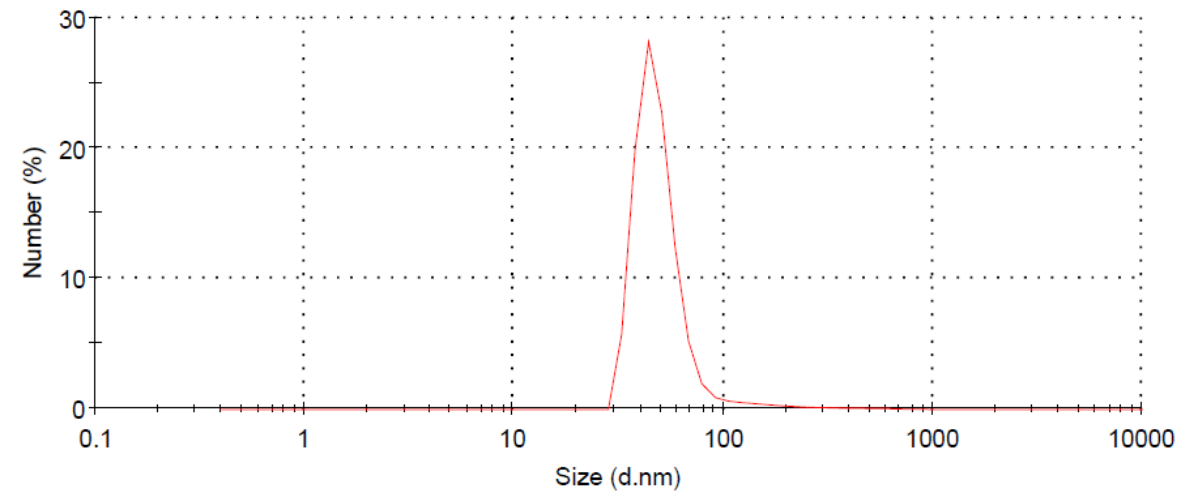

Figure.5: particle size distribution graph of precipitated silica obtained by DLS analysis

There is a difference between this value and the value of experiment No.9 in table.1. The reason of difference between these two values is that the methods of measuring particle size are different in each case. Because DLS analysis is more precise than image analysis results, the last value which obtained from DLS is more reliable.

$\mathrm{X}$-Ray fluorescence showed that the produced silica had high purity with minor amounts of $\mathrm{Na}_{2} \mathrm{O}, \mathrm{K}_{2} \mathrm{O}$, $\mathrm{Al}_{2} \mathrm{O}_{3}$, and $\mathrm{Fe}_{2} \mathrm{O}_{3}$ (Table 2).

Table 2: XRF analysis of produced silica

\section{Component Percentage (\%)}

\begin{tabular}{|cl|}
\hline $\mathrm{SiO}_{2}$ & 99.3 \\
\hline $\mathrm{Al}_{2} \mathbf{O}_{3}$ & 0.44 \\
\hline $\mathrm{Fe}_{2} \mathrm{O}_{3}$ & 0.06 \\
\hline $\mathrm{Na}_{2} \mathbf{O}$ & 0.02 \\
\hline $\mathrm{CaO}$ & 0.15 \\
\hline $\mathrm{K}_{2} \mathbf{O}$ & 0.03 \\
\hline
\end{tabular}

\section{Conclusions}

Silica nano particles were produced by reaction of sodium meta silicate with sulfuric acid at pH7. Results are summarized as:

1 - Particle size of precipitated silica decreased with increasing of sodium silicate and SDS concentrations.

2 - Particle size of $44 \mathrm{~nm}$ was achieved at 20\%Na2SiO3 and 200ppm SDS.

3 - With decreasing the size of silica particles degree of agglomeration and uniform dispersity of silica particle increased.

4 - The produced silica had the following specifications; 99.3\% purity, amorphous with narrow size distribution.

\section{Acknowledgment}

Authors wish to thank the Sharif Nano Pigment Co. (SNP) for their immense support and supply of raw retreading compounds. Also, special thanks to the members of laboratories of the institute of colorants, paints\& coatings (ICPC) for their cooperation in this work. 


\section{References}

[1] Bogush G H, Tracy M A, Zukoski C F. 1988 Preparation of monodisperse silica particles: Control of size and mass fraction. J Non-Cryst Solids; 104: 95-106.

[2] Kaushik P, Rajasekar R, Kang D J, Zhang Z X, Samir K PI, Chapal K D, Kim J K. 2010 Effect of fillers on Natural Rubber/ High Styrene Rubber blends with nano silica Morphology and Wear. Materials and Design; 31:677-686.

[3] Davies G L, Barry A, Gunko Y K. 2009 Preparation and size optimisation of silica nanoparticles using statistical analyses. Chemical Physics Letters ; 468 : 239-244.

[4] Bogush G H, Zukoski C F. 1991 Studies of the Kinetics of the Precipitation of Uniform Silica Particles through the Hydrolysis and Condensation of Silicon Alkoxides. J Colloid Interface Sci; 142: 19-34.

[5] Hessien M M, Rashad M M, Zaky R R, Abdel-Aal E A, El-Barawy K A. 2009 Controlling the synthesis conditions for silica nanosphere from semi-burned rice straw. Materials Science and Engineering B; 162:14-21.

[6] Li X, Zhi Cao, Zhang Z, Dang H. 2006 Surface-modification in situ of nano-SiO2 and its structure and tribological properties. Applied Surface Science; 252: 7856-7861.

[7] Arriagada F J, ] Osseo-Asare K. 1992 Phase and dispersion stability effects in the synthesis of silica nanoparticles in a non-ionic reverse microemulsion. Colloids and Surfaces; 69:105-115.

[8] Osseo-Asare K, Arriagada F J. 1990 Preparation of SiO2 nanoparticles in a non-ionic reverse micellar system. J Colloids and Surfaces; 50: 321-339.

[9] Yamauchi H, Ishikawa T, Kondo S. 1989 Surface characterization of ultramicro spherical particles of silica prepared by w/o microemulsion method. Colloids and Surfaces; 37: 71-80. 